\title{
Using the agility ladder in improving the performance level of some composite offensive skills in basketball among the students of the Faculty of Physical Education
}

\section{Dr. Nada Mahfouz Abd Al-Azim Kapoh*}

\section{Introduction and Research Problem:}

Scientific advances in the field of sport was not a mere chance, but was the result of efforts by specialists academic and applied domains to improve all the learner's skills in the various levels and sports.

Basketball is one of the team sports that was clearly and positively influenced by the advances in the different tools and devices in the field of sports (Hashim, 2002: 15).

Several approaches for teaching and developing the skills of this game emerged. There is the traditional approach that relies on the repetition of skills performance, progressing gradually from easier to harder skills, then moving to small details. More recent approaches tend to use technological means and auxiliary training tools in teaching and improving the performance of skills and how they can be used in the game.

The agility ladder is one of the best tools that help teach movement patterns. It is easy to use and employ in difference exercise, helps move the feet in various directions that promote agility, flexibility and speed as well as improve the motor skills which are similar to the exercise of the agility ladder (www.selfgrowth.com).

The different types of basketball skills are the basic foundation of the game. Without mastering these skills, the player will not be able to fully implement the tactics and duties of his/her position (Moawad, 1980; Shams Eddin, 1994; El-Nemr \& Sayed, 1998).

A realistic look at the technical development in basketball shows us that it is difficult that teaching, training, and evaluating basic skills remain separate, as the use of composite offensive skills increased as it an important means of overcoming defensive methods.

Additionally, an important educational goal in basketball is to learn and master the skills and tactical performance, since it is necessary to keep up with the advancing means and tools to make the educational process successful and allowing the students to acquire the different basketball skills.

The researcher noticed through her observations and experience as instructor of the basketball course at the Faculty of Physical Education, the poor performance level of composite offensive skills in basketball among the students. This is due to the lack of using auxiliary tools that help develop and improve the performance level of such skills. Most of the skills exercises are performed using balls or other ordinary tools, which reduces its benefit.

Thus, the idea of the research emerged in order to demonstrate the importance of auxiliary tools and incorporating them in the educational process by using the agility ladder in performing agility and speed exercises that are related to the direction of performing movement pathways of the composite offensive skills which compose the curricular content of the basketball course for fourth year female students, so as to ensure the more improvement of these skills than the traditional method.

\footnotetext{
* Instructor, Games Department, Faculty of Physical Education, Menoufya University, El-Sadat City
} 


\section{Research Purpose:}

This research aims at identifying the effect of using the agility ladder on improving the performance level of some composite offensive basketball skills among students at the Faculty of Physical Education.

\section{Research Hypotheses:}

1. There are statistically significant differences between the means of pre-test and post-test measurements of the control group in the level of the composite offensive basketball skills under research in favor of the post-test measurement.

2. There are statistically significant differences between the means of pre-test and post-test measurements of the experimental group in the level of the composite offensive basketball skills under research in favor of the post-test measurement.

3. There are statistically significant differences between the means of post-test measurements of the control group and the experimental group in the level of the composite offensive basketball skills under research in favor of the experimental group.

4. There are differences between mean improvement rates of the control and experimental groups' post-test measurements in the level of the composite offensive basketball skills under research in favor of the experimental group.

\section{Research Terms:}

Agility ladder: is composed of two long tapes connected by plastic separators (in the shape of a ladder) where the students perform foot exercises or faking so that they do not touch the tapes or the separators of the ladder (operational definition)

\section{Previous studies:}

1. Zeinab Awad (2015): this study found that using some auxiliary tools with the research sample was valid and successful in teaching them the shooting skill in basketball. The auxiliary tools also achieved more positive results than the traditional method used in teaching the shooting skill in basketball. The study recommended using auxiliary tools in teaching skills of various sports.

2. Syarulniza Abdul Jamil, et al. (2015): found significant differences in the improvement of agility in the research experimental sample compared to the improvement in the control sample. They recommended the use of agility ladder exercises for developing the agility level.

3. Chandrakumar \& Ramesh (2015): found improvement in agility, speed, and the studied skills in the research experimental group compared to the control group. They recommended the use of agility ladder in training physical aspects and badminton skills.

4. Srinivasan \& Saikumar (2012): found great improvement in the performance level of the skills and physical variables of badminton in the research sample of female students, as statistically significant differences were found between the post-test measurements of the control group and the experimental group in favor of the latter.

5. A study by Ayed Hussein (2012) found that using training means in training modules effectively influenced the development of sensory perception, motor coordination, and accuracy of shooting forms with the basketball among the members of the experimental group. Additionally, the method prepared and followed by the coach had a remarkable positive role in the development of sensory perception, motor 
coordination, and accuracy of shooting forms with the basketball in the control group. The experimental group outperformed the control group in the sensory perception, motor coordination, and accuracy of shooting forms with the basketball tests. The training means also added the element of thrilling and excitement to the application of exercises related to the shooting skill especially with youth players, and the specificity of the skill.

6. Elmarie Terblanche \& Ranel E. Venter's study (2009) found statistically significant differences between the post-test measurements of the experimental and control groups in favor of the experimental group in the studied variables. It recommended incorporating agility ladder exercises in the teaching and training programs of badminton motor skills.

7. Mazen Jasim's study (2008) found that using an auxiliary tool to develop the accuracy of scoring goals from a free throw had a positive impact on developing accuracy and showing statistically significant differences between the results of preand post-tests of the control group and the experimental group. The experimental group also showed noticeable and greater improvement than the control group in the pos-test results of the accuracy of scoring goals from a free throw.

\section{Commenting on previous studies:}

Previous studies were presented in light of their findings and recommendations, which helped the researcher determine the research main variable, the main themes of the procedures, statistical treatments appropriate for checking the hypotheses and confirming the results found.

\section{Research Procedures:}

A. Research Method:

The researcher used the experimental method with two groups: an experimental group and a control group, and took pre-test and post-test measurements for each group.

B. Research Sample:

The research sample was purposively selected from the fourth year students at the Faculty of Physical Education, Al-Sadat University, for the academic year 2012/13. The sample size consisted of 50 female students before administering the experiment and was divided into three groups: an experimental group, a control group (each consisted of 20 female students) and a group composed of 10 female students for administering the exploratory study. Homogeneity of the research sample:

The researcher conducted homogeneity between fourth year students (of the research sample) in terms of some growth rates, some specific physical variables that are directly related to the agility ladder exercises, and composite offensive skills in basketball that are taught in the basketball curriculum to the fourth year (female) students at the Faculty of Physical Education, Al-Sadat University, during the first term of the academic year 2012/13, to confirm that the sample falls below the normal curve, as shown in table 1. 
Table 1: Homogeneity of the Research Sample in Some Selected Variables $N=50$

\begin{tabular}{|c|c|c|c|c|c|c|}
\hline \multicolumn{2}{|c|}{ Studied variables } & $\begin{array}{l}\text { Measurement } \\
\text { unit }\end{array}$ & Mean & Median & SD & Skewness \\
\hline \multirow{3}{*}{ 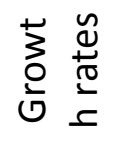 } & Age & year & 20.33 & 20.00 & 1.20 & 0.82 \\
\hline & Height & $\mathrm{Cm}$ & 161.72 & 161.00 & 3.57 & 0.61 \\
\hline & Weight & $\mathrm{Kg}$ & 60.29 & 61.00 & 4.91 & -0.43 \\
\hline \multirow{4}{*}{ 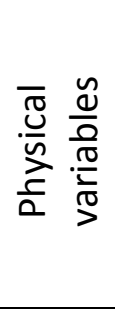 } & $\begin{array}{l}\text { Speed- } \\
\text { Strength }\end{array}$ & $\mathrm{Cm}$ & 25.61 & 25.00 & 3.69 & 0.50 \\
\hline & $\begin{array}{c}\text { Transitional } \\
\text { speed }\end{array}$ & Second & 5.93 & 5.64 & 0.76 & 1.14 \\
\hline & Agility & Second & 31.27 & 30.66 & 2.09 & 0.88 \\
\hline & Flexibility & $\mathrm{Cm}$ & 10.18 & 9.00 & 2.78 & 1.27 \\
\hline
\end{tabular}

Table 1 shows that skewness coefficients ranged between -0.43 and 1.27, i.e. they fell in the range \pm 3 , indicating the homogeneity of the research sample in the variables listed in the table.

C. Data Collection Tools and Devices:

1. Growth rates:

- Age: with reference to the birth date and approximated to the nearest year.

- Height: measured by Restameter and the measurement unit is the centimeter.

- Weight: measured by a scale and the measurement unit is the kilogram.

2. Special physical variables and main skills:

In determining the specific physical variables and the composite offensive basketball skills and the tests related to both of them, the researcher relied on several applied scientific studies in basketball which applied these tests and calculated their scientific coefficients. These studies include Mohamed Belal (1997), Manal Mohamed (1998), Mohamed Abdel Dayem and Sobhy Hassanein (1999), Nada Kapoh (2007a), and Nada Kapoh (2007b).

a. Specific physical variables tests: (Hassanein, 1987: 240-378)

- Sargent vertical jump test to measure speed-strength

- 30-meter sprint test from a moving start to measure transitional speed.

- Barrow zigzag run test to measure agility

- Sit and reach test to measure flexibility.

b. Studied composite offensive skills: attachment 1 (Kapoh, 2007b: 170-180)

The researcher determined the studied composite offensive basketball skills and the appropriate tests to measure them in light of the technical content of the basketball course for fourth-year students at the Faculty of Physical Education, Al-Sadat University, during the first term of the academic year 2012/13 as follows:

- Catching and receiving the ball then passing it test

- Catching and receiving the ball then faking then passing it test

- Catching and receiving the ball then shooting test

- Catching and receiving the ball then faking then shooting test

3. Data recording forms (attachment 2)

D. Tools and devices used in the research

- Restameter to measure height to the nearest centimeter 
- Scale to measure weight to the nearest kilogram

- Basketball field, legal basketball goal

- Legal basketballs

- Stopwatch to the nearest 0.01 second, measuring tape by meter

- Lime, chalk, cones, separators, whistle

- Smooth wall, gymnastic mattresses, table

- Agility ladder (attachment 3)

E. Exploratory Studies

1. First exploratory study

The first exploratory study was conducted from Monday, 1 October to Thursday, 4 October 2012 with the sample assigned to the exploratory study (10 female students). It aimed to:

- Review the conditions and specifications of the studied composite offensive skills in basketball tests.

- Organize and coordinate the tests work progress.

- $\quad$ Validate the tools and data recording forms used in the study.

- Train the assistants (two assistants) on implementing and administering the tests, and filling the data recording forms, in order to ensure the accuracy and speed of measurement (attachment 5).

- Determine the suitable distance between the agility ladder separators that will be used in the core sample's training. This was achieved by making the exploratory sample perform different types of exercises using the agility ladder. The suitable distance between separators was determined to be $40 \mathrm{~cm}$ (attachment 3 ).

- Select agility ladder exercises of the research core sample.

2. The second exploratory study:

It was conducted from Saturday, 6 October through Sunday, 14 October 2012. It aimed to ensure the scientific validity and reliability of the specific physical variable tests and the composite offensive basketball skills tests being studied.

\section{a. Calculating the tests validity:}

Validity coefficients were calculated suing discriminate validity by finding $p$-value of the differences between the upper and lower quartiles. The researcher arranged the sample's score $(N=50)$ in a descending order, then calculated the significance of differences between the means of the two quartiles. Table 2 outlines the validity coefficients of the tests under research.

Table 2: Validity coefficients of the tests under research N1 $=\mathrm{N} 2=13$

\begin{tabular}{|c|c|c|c|c|c|c|c|}
\hline \multirow{2}{*}{\multicolumn{2}{|c|}{ Studied variables }} & \multirow{2}{*}{$\begin{array}{c}\text { Measurement } \\
\text { unit }\end{array}$} & \multicolumn{2}{|c|}{ Upper quartile } & \multicolumn{2}{|c|}{ Lower quartile } & \multirow{2}{*}{$\begin{array}{c}\text { Calculated } \\
t \text { value }\end{array}$} \\
\hline & & & $M$ & SD士 & $M$ & SD \pm & \\
\hline \multirow{4}{*}{ 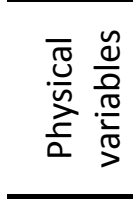 } & Speed-Strength & $\mathrm{Cm}$ & 27.43 & 2.71 & 23.50 & 2.26 & $7.80^{*}$ \\
\hline & Transitional speed & Second & 5.18 & 0.69 & 6.73 & 0.75 & $10.65 *$ \\
\hline & Agility & Second & 30.63 & 0.94 & 32.65 & 1.12 & $9.67^{*}$ \\
\hline & Flexibility & $\mathrm{Cm}$ & 12.04 & 1.38 & 8.62 & 1.25 & $12.86 *$ \\
\hline \multirow{2}{*}{ 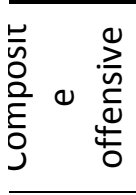 } & $\begin{array}{l}\text { Catching and receiving } \\
\text { the ball then passing it }\end{array}$ & Point & 43.45 & 3.67 & 37.27 & 3.20 & $8.88^{*}$ \\
\hline & $\begin{array}{l}\text { Catching and receiving } \\
\text { the ball then faking }\end{array}$ & Point & 42.20 & 3.90 & 36.82 & 4.19 & $6.58^{*}$ \\
\hline
\end{tabular}




\begin{tabular}{|c|c|c|c|c|c|c|}
\hline then passing it & & & & & & \\
\hline $\begin{array}{l}\text { Catching and receiving } \\
\text { the ball then shooting }\end{array}$ & Point & 41.36 & 3.39 & 36.34 & 3.89 & $6.81 *$ \\
\hline $\begin{array}{l}\text { Catching and receiving } \\
\text { the ball then faking } \\
\text { then shooting }\end{array}$ & Point & 40.23 & 4.15 & 35.48 & 3.76 & $5.94 *$ \\
\hline
\end{tabular}

* value of tabular $t$ at statistical significance of 24 and $p$-value $(0.05)=2.064$

Table 2 shows that statistically significant differences exist at $p$ level (0.05) between the means of the upper and lower quartiles in favor of the upper quartile in the tests under research, indicating the validity of these tests.

\section{b. Calculating reliability coefficients of the tests under research:}

The researcher calculated the reliability coefficients using the test-retest method with a time interval of 5 days between the test and retest of the sample assigned to the exploratory study. Table 3 shows the reliability coefficients of the tests under research.

Table 3: Reliability coefficients of the tests under research N1 $=10$

\begin{tabular}{|c|c|c|c|c|c|c|c|}
\hline \multirow{2}{*}{\multicolumn{2}{|c|}{ Studied variables }} & \multirow{2}{*}{$\begin{array}{l}\text { Measurement } \\
\text { unit }\end{array}$} & \multicolumn{2}{|c|}{ Test } & \multicolumn{2}{|c|}{ Re-test } & \multirow{2}{*}{$\begin{array}{l}\text { Calculated } \\
r \text { value }\end{array}$} \\
\hline & & & $M$ & $\mathrm{SD} \pm$ & $M$ & $\mathrm{SD} \pm$ & \\
\hline \multirow{4}{*}{ 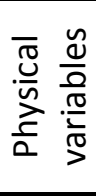 } & Speed-Strength & $\mathrm{Cm}$ & 24.82 & 3.14 & 25.11 & 2.90 & $0.86^{*}$ \\
\hline & Transitional speed & Second & 5.86 & 0.78 & 5.79 & 0.67 & $0.91^{*}$ \\
\hline & Agility & Second & 31.50 & 2.42 & 31.24 & 2.30 & $0.88^{*}$ \\
\hline & Flexibility & $\mathrm{Cm}$ & 8.97 & 2.70 & 9.01 & 2.65 & $0.96 *$ \\
\hline \multirow{4}{*}{ 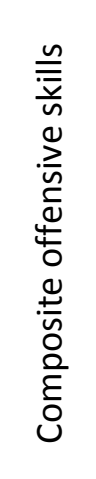 } & $\begin{array}{l}\text { Catching and receiving } \\
\text { the ball then passing it }\end{array}$ & Point & 41.36 & 4.09 & 42.15 & 3.76 & $0.85^{*}$ \\
\hline & $\begin{array}{l}\text { Catching and receiving } \\
\text { the ball then faking } \\
\text { then passing it }\end{array}$ & Point & 39.71 & 4.49 & 40.28 & 4.11 & $0.82^{*}$ \\
\hline & $\begin{array}{l}\text { Catching and receiving } \\
\text { the ball then shooting }\end{array}$ & Point & 38.22 & 5.62 & 38.93 & 4.89 & $0.79 *$ \\
\hline & $\begin{array}{l}\text { Catching and receiving } \\
\text { the ball then faking } \\
\text { then shooting }\end{array}$ & Point & 35.26 & 5.98 & 36.04 & 5.07 & $0.74^{*}$ \\
\hline
\end{tabular}

* value of tabular $r$ at statistical significance of 8 and $p$-value $(0.05)=0.632$

Table 3 shows that correlations between the test and retest of the examined research tests have significance at $p$ level of 0.05 ranged between 0.74 and 0.96 which are high values, reflecting that the tests under research have an acceptable level of reliability.

F. Timeline of implementing the main study:

1. Pre-test measurements:

After confirming the validity and reliability of the composite offensive basketball skills tests and completing all the procedures, the pre-test measurements were taken for both the experimental group and the control group on Wednesday, 17 and Thursday, 18 October 2012. The researcher and the assistants took into account unifying the tests measurement procedures of the research sample. 
Table 4: Equivalence of the experimental group and the control group (the research sample) in the level of the studied composite offensive basketball skills N1 = N2 = 20

\begin{tabular}{c|c|c|c|c|c|c}
\hline \hline $\begin{array}{c}\text { Composite } \\
\text { offensive skills in } \\
\text { basketball tests }\end{array}$ & $\begin{array}{c}\text { Measurement } \\
\text { Unit }\end{array}$ & \multicolumn{2}{|c|}{ Control Group } & \multicolumn{2}{|c|}{$\begin{array}{c}\text { Experimental } \\
\text { Group }\end{array}$} & $\begin{array}{c}\text { Calculated } \\
\boldsymbol{t} \text { value }\end{array}$ \\
\cline { 3 - 6 } $\begin{array}{c}\text { Catching and } \\
\text { receiving the ball } \\
\text { then passing it }\end{array}$ & Point & 41.76 & 8.89 & 42.96 & 7.29 & 0.73 \\
\hline $\begin{array}{c}\text { Catching and } \\
\text { receiving the ball } \\
\text { then faking then } \\
\text { passing it }\end{array}$ & Point & 40.03 & 9.12 & 41.38 & 7.86 & 0.78 \\
\hline $\begin{array}{c}\text { Catching and } \\
\text { receiving the ball } \\
\text { then shooting }\end{array}$ & Point & 38.78 & 9.92 & 39.65 & 9.31 & 0.45 \\
\hline $\begin{array}{c}\text { Catching and } \\
\text { receiving the ball } \\
\text { then faking then } \\
\text { shooting }\end{array}$ & Point & 35.69 & 10.21 & 36.82 & 9.74 & 0.56 \\
\hline \hline
\end{tabular}

* value of tabular $t$ at statistical significance of 38 and $p$-value $(0.05)=2.021$

Table 4 shows that there are no significant differences at $p$ level of 0.05 between the means of the pre-test measurements of the experimental and the control groups in the examined composite offensive skills in basketball, indicating the equivalence of the two groups of the research sample before conducting the main study.

\section{Conducting the main study:}

The main study was conducted during the first term of the academic year 2012/13 from Saturday, 20 October to Thursday, 13 December 2012, taking into account the schedule and curriculum of the basketball course of the students in the research sample. The traditional method was used with the control group and the agility ladder was used with the experimental group as follows:

\begin{tabular}{|l|l|}
\hline Duration of the experiment & Eight weeks \\
\hline Number of educational modules & Eight modules (one per week) \\
\hline Total duration of the educational module & 90 minutes \\
\hline Duration of using the agility ladder & $\begin{array}{l}45 \text { minutes in each educational module, } \\
\text { starting after the warm-up part of the } \\
\text { educational module }\end{array}$ \\
\hline Agility ladder exercises (22) & Attachment 4 \\
\hline
\end{tabular}

\section{Post-test measurements:}

The post-test measurements of the two groups were taken by the composite offensive basketball skills test under research on Saturday 15 and Sunday 16 December 2012.

G. Statistical Treatment:

The researcher used SPSS program to statistically treat the data. She used the following statistical techniques: the Mean, Standard Deviation, Median, Skewness coefficient, $t$ test, Pearson simple correlation coefficient, improvement rate percentage. The researcher accepted a significance at $p$ value 0.05 . 


\section{Results and Discussion}

Table 5: Significance of differences between the Means of the pre-test and post-test measurements of the control group in the studied composite offensive basketball skills $\quad N=20$

\begin{tabular}{c|c|c|c|c|c|c}
\hline \hline $\begin{array}{c}\text { Composite offensive } \\
\text { skills in basketball } \\
\text { tests }\end{array}$ & \multicolumn{2}{|c|}{$\begin{array}{c}\text { Pre-test } \\
\text { measurement }\end{array}$} & \multicolumn{2}{c|}{$\begin{array}{c}\text { Post-test } \\
\text { measurement }\end{array}$} & \multirow{2}{*}{$\begin{array}{c}\text { Calculated } \boldsymbol{t} \\
\text { value }\end{array}$} & $\begin{array}{c}\text { Improvement } \\
\text { rates \% }\end{array}$ \\
\cline { 2 - 5 } & $\mathbf{M}$ & $\mathbf{S D} \pm$ & $\mathbf{M}$ & $\mathbf{S D} \pm$ & & \\
\hline $\begin{array}{c}\text { Catching and receiving } \\
\text { the ball then passing it }\end{array}$ & 41.76 & 8.89 & 49.02 & 6.11 & $4.71^{*}$ & $17.39 \%$ \\
\hline $\begin{array}{c}\text { Catching and receiving } \\
\text { the ball then faking } \\
\text { then passing it }\end{array}$ & 40.03 & 9.12 & 47.50 & 6.79 & $4.60^{*}$ & $18.66 \%$ \\
\hline $\begin{array}{c}\text { Catching and receiving } \\
\text { the ball then shooting }\end{array}$ & 38.78 & 9.92 & 45.15 & 7.84 & $3.53^{*}$ & $16.43 \%$ \\
\hline $\begin{array}{c}\text { Catching and receiving } \\
\text { the ball then faking } \\
\text { then shooting }\end{array}$ & 35.69 & 10.21 & 41.03 & 8.08 & $2.87^{*}$ & $14.96 \%$ \\
\hline \hline
\end{tabular}

* value of tabular $t$ at statistical significance of 19 and $p$-value $(0.05)=1.729$

Table 5 and figure 1 demonstrate statistically significant differences at $p$ level 0.05 between the means of pre-test and post-test measurements of the control group in the level of composite the studied offensive basketball skills in favor of the post-test measurement.

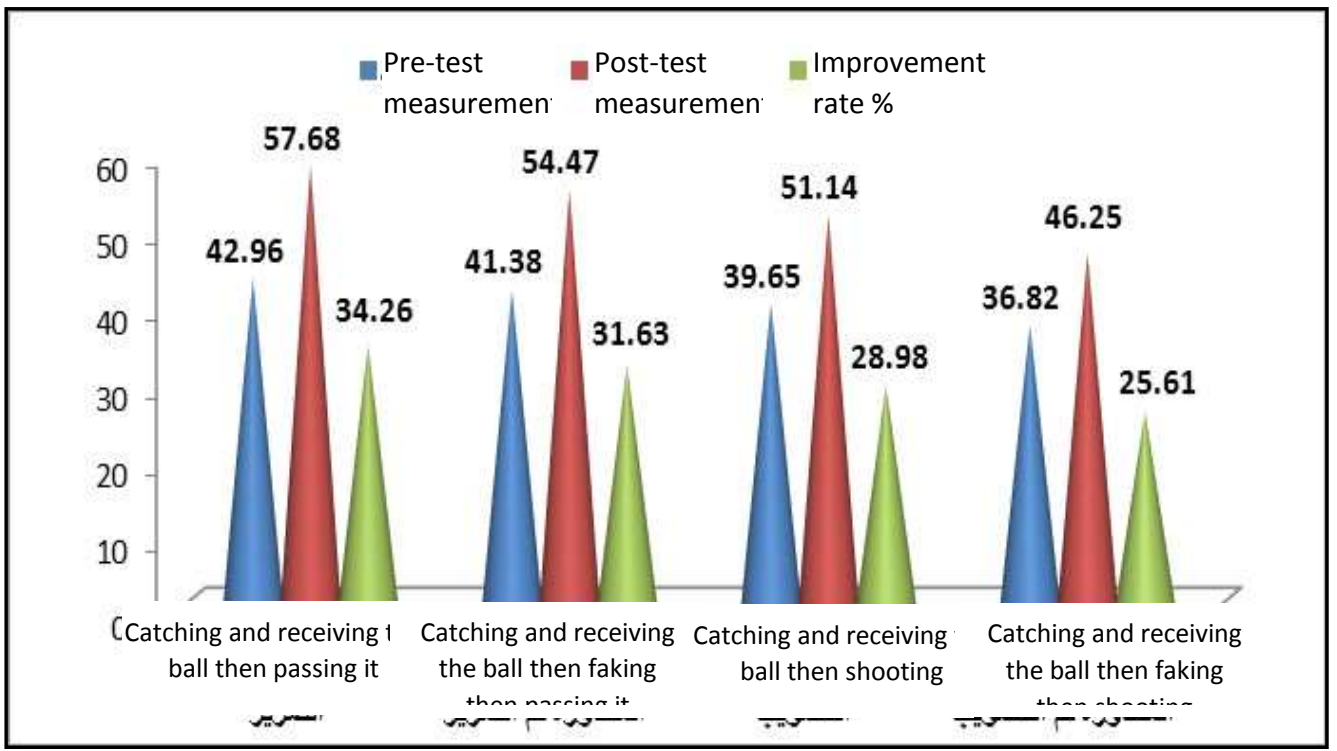

Figure 1: Means of the pre-test and post-test measurements of the control group in the studied composite offensive basketball skills

Table 5 and figure 1 also show differences between the pre-test and post-test measurements in the improvement rates of the control group's level of the studied composite offensive basketball skills in favor of the post-test measurement.

The researcher attributes these differences to the use of the traditional educational program followed at the Faculty of Physical Education, as it includes the repetition of exercises of the studied composite offensive basketball skills, which contributed to the 
improvement of the students' performance. The numerous repetition of exercises performed by the students during the practical application helped automatically acquire the researched skills and improve them.

This finding is similar to the findings by Jasim (2008) and Hussein (2012) statistically significant differences existed between the means of the pre-test and post-test measurements of the control group as a result of the program used with it.

This finding supports the first hypothesis which reads: "There are statistically significant differences between the means of pre-test and post-test measurements of the control group in the level of the composite offensive basketball skills under research in favor of the post-test measurement."

Table 6: Significance of differences between the Means of the pre-test and post-test measurements of the experimental group in the studied composite

offensive basketball skills

$N=20$

\begin{tabular}{|c|c|c|c|c|c|c|}
\hline \multirow{2}{*}{$\begin{array}{c}\text { Composite offensive } \\
\text { skills in basketball } \\
\text { tests }\end{array}$} & \multicolumn{2}{|c|}{$\begin{array}{c}\text { Pre-test } \\
\text { measurement }\end{array}$} & \multicolumn{2}{|c|}{$\begin{array}{c}\text { Post-test } \\
\text { measurement }\end{array}$} & \multirow{2}{*}{$\begin{array}{l}\text { Calculated } t \\
\text { value }\end{array}$} & \multirow{2}{*}{$\begin{array}{l}\text { Improvement } \\
\text { rates } \%\end{array}$} \\
\hline & $M$ & SD \pm & $M$ & SD \pm & & \\
\hline $\begin{array}{l}\text { Catching and receiving } \\
\text { the ball then passing it }\end{array}$ & 42.96 & 7.29 & 57.68 & 7.10 & $10.13^{*}$ & $34.26 \%$ \\
\hline $\begin{array}{l}\text { Catching and receiving } \\
\text { the ball then faking } \\
\text { then passing it }\end{array}$ & 41.38 & 7.86 & 54.47 & 7.93 & $8.21^{*}$ & $31.63 \%$ \\
\hline $\begin{array}{l}\text { Catching and receiving } \\
\text { the ball then shooting }\end{array}$ & 39.65 & 9.31 & 51.14 & 9.80 & $5.95^{*}$ & $28.98 \%$ \\
\hline $\begin{array}{l}\text { Catching and receiving } \\
\text { the ball then faking } \\
\text { then shooting }\end{array}$ & 36.82 & 3.74 & 46.25 & 8.67 & $5.06 *$ & $25.61 \%$ \\
\hline
\end{tabular}

Table 6 and figure 2 demonstrate statistically significant differences at $p$ level of 0.05 between the means of the pre-test and post-test measurements of the experimental group in the level of the studied composite offensive basketball skills in favor of the post-test measurement. 


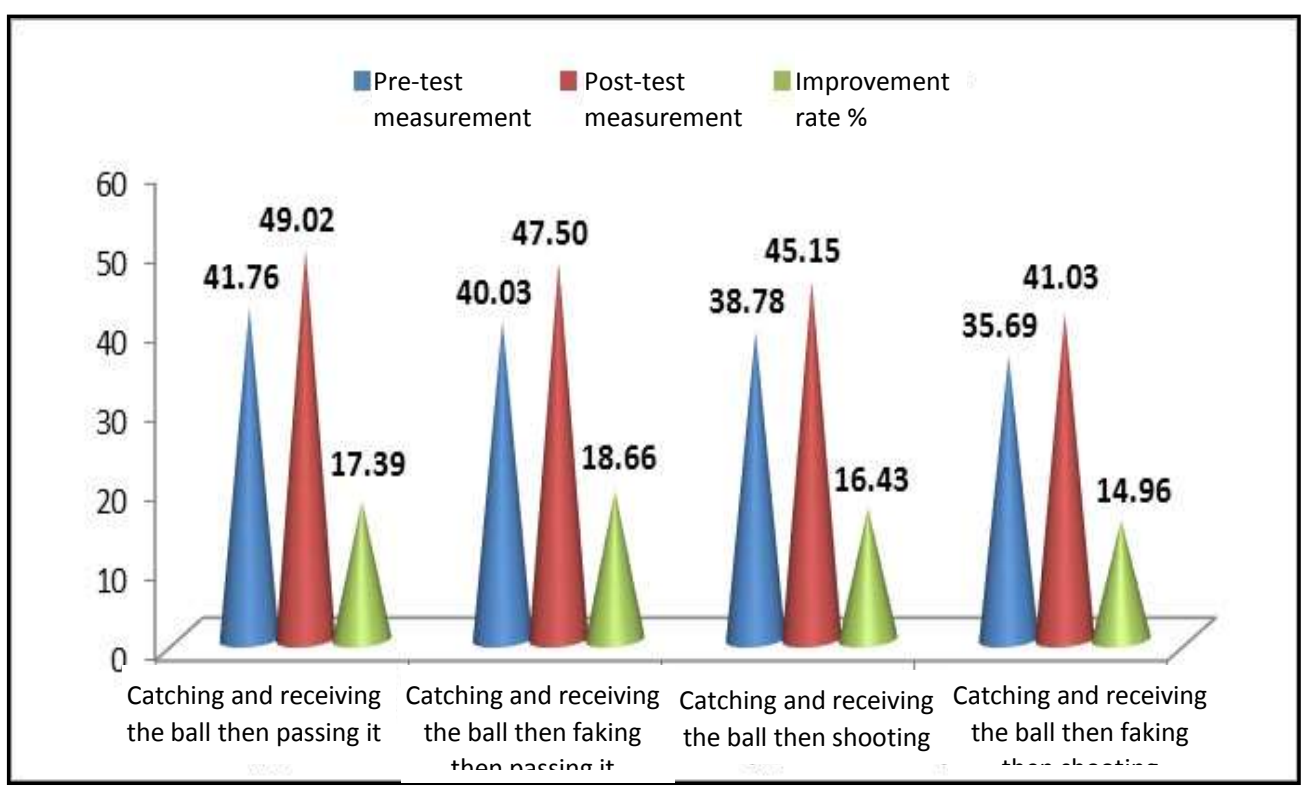

Figure 2: Means of the pre-test and post-test measurements of the experimental group in the studied composite offensive basketball skills

Table 6 and figure 2 also show differences between the experimental group's pre-test and post-test measurements in the improvement rates in the level of the studied composite offensive basketball skills in favor of the post-test measurement.

The researcher attributes these differences to the use of the agility ladder that contributed in the improvement of the performance of the studied composite offensive basketball skills, as the stages of executing these skills resemble the motion pathways and the characteristics of agility ladder exercises. This led to an increase in the effectiveness of composite skills exercises when performed with the agility ladder, which was reflected in turn on the overall improvement of the level of performance of the studied composite skills.

This finding is similar with the findings by Jasim (2008), Hussein (2012), Awad (2015), and Abdul Jamil et al. (2015) that statistically significant differences existed between the means of the pre-test and post-test measurements of the experimental group due to the use of auxiliary tools in the educational or the training process.

It is also consistent with Abd Alima's (2012) remark that the attention to auxiliary tools in the educational process through employing them to serve the process of teaching the students became evident recently, since the traditional method used without incorporating or using auxiliary tools consumes a great deal of time and effort to improve the level of performing students' motor skills (Abd Alima, 2012: 19).

This finding supports the second hypothesis which reads: "There are statistically significant differences between the means of pre-test and post-test measurements of the experimental group in the level of the composite offensive basketball skills under research in favor of the post-test measurement". 
Table 7: Significance of differences between the Means of the post-test measurements of the control and experimental groups in the studied composite offensive basketball skills $\quad N 1=N 2=20$

\begin{tabular}{|c|c|c|c|c|c|c|}
\hline \multirow{2}{*}{$\begin{array}{l}\text { Composite offensive } \\
\text { skills in basketball } \\
\text { tests }\end{array}$} & \multicolumn{2}{|c|}{ Control Group } & \multicolumn{2}{|c|}{$\begin{array}{l}\text { Experimental } \\
\text { Group }\end{array}$} & \multirow{2}{*}{$\begin{array}{l}\text { Calculated } t \\
\text { value }\end{array}$} & \multirow{2}{*}{$\begin{array}{l}\text { Improvement } \\
\text { rates \% }\end{array}$} \\
\hline & $\mathbf{M}$ & SD \pm & $\mathbf{M}$ & SD \pm & & \\
\hline $\begin{array}{l}\text { Catching and receiving } \\
\text { the ball then passing it }\end{array}$ & 49.02 & 6.11 & 57.68 & 7.10 & $6.47^{*}$ & $17.67 \%$ \\
\hline $\begin{array}{l}\text { Catching and receiving } \\
\text { the ball then faking } \\
\text { then passing it }\end{array}$ & 47.50 & 6.79 & 54.47 & 7.93 & $4.67^{*}$ & $14.67 \%$ \\
\hline $\begin{array}{l}\text { Catching and receiving } \\
\text { the ball then shooting }\end{array}$ & 45.15 & 7.84 & 51.14 & 9.80 & $3.34^{*}$ & $13.27 \%$ \\
\hline $\begin{array}{l}\text { Catching and receiving } \\
\text { the ball then faking } \\
\text { then shooting }\end{array}$ & 41.03 & 8.08 & 46.25 & 8.67 & $3.08 *$ & $12.72 \%$ \\
\hline
\end{tabular}

* value of tabular $t$ at statistical significance of 38 and $p$-value $(0.05)=1.684$

Table 7 and figure 3 show that there are statistically significant differences at $p$ level 0.05 between the means of the post-test measurements of the control and experimental groups in the studied composite offensive basketball skills in favor of the experimental group.

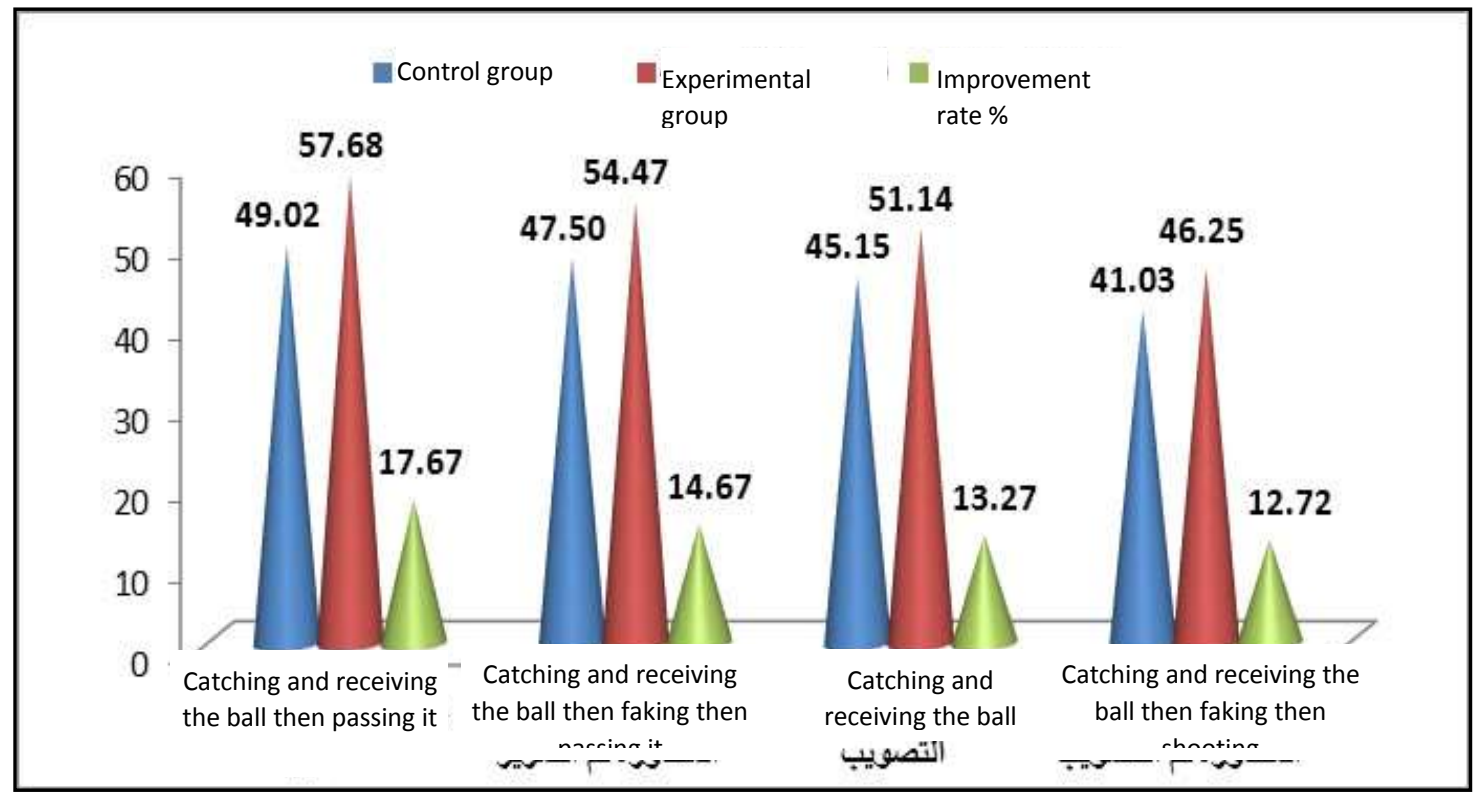

Figure 3: Means of the post-test measurements of the control and experimental groups in the studied composite offensive basketball skills

The researcher attributes these differences to the use of the agility ladder in the experimental group's program, which effectively influenced the improvement in the performance of the studied composite offensive basketball skills compared to the control group which used the traditional educational program followed at the Faculty. Additionally, the use of the agility ladder added the element of excitement and interest to the exercises of the experimental group.

This finding is similar to the findings of Terblanche and Venter (2009), Srinivasan \& Sikumar (2012), Hussein (2012) and Awad (2015) that indicated significant differences 
between the means of the post-test measurements of the control and experimental groups in favor of the experimental group. They attributed these differences to the use of auxiliary tools in the experimental group's program.

This finding supports the third hypothesis, which reads: "There are statistically significant differences between the means of post-test measurements of the control group and the experimental group in the level of the composite offensive basketball skills under research in favor of the experimental group".

Furthermore, table 7 and figure 3 show differences in the improvement rates between the means of the post-test measurements of the two groups (the control group and the experimental group) in favor of the experimental group. The skill of catching and receiving the ball then passing it came first as the improvement rate was $17.67 \%$, the skill of catching and receiving the ball then faking then passing it came second with an improvement rate of $14.67 \%$, the skill of catching and receiving the ball then shooting came third as its improvement rate was $13.27 \%$, and the skill of catching and receiving the ball then faking then shooting came fourth with an improvement rate of $12.72 \%$.

The researcher attributes the supremacy of the experimental group's results in the improvement of performing composite offensive basketball skills relative to the control group to the employment of the agility ladder exercises within the content of the experimental group's program, which agree and conform with the motion pathways of the studied composite skills.

This finding is consistent with the findings of other studies that addressed auxiliary tools and agility ladder such as the studies by Awad (2015), Abdul Jamil et al. (2015), Chandrakumar and Ramesh (2015) which found more improvement in the level of performing the research variables in the experimental group as a result of using auxiliary tools compared to the control group that relied on the traditional program.

This result supports the fourth hypothesis, which reads: "There are differences between mean improvement rates of the control and experimental groups' post-test measurements in the level of the composite offensive basketball skills in favor of the experimental group".

\section{Conclusions:}

In light of the research objectives and hypotheses, the used method, and the results of the statistical analysis, the researcher reached the following conclusions:

1. There are statistically significant differences at $p$ level 0.05 between the means of the pre-test and post-test measurements of the control group in the level of the studied composite offensive basketball skills, in favor of the post-test measurement.

2. There are statistically significant differences at $p$ level 0.05 between the means of the pre-test and post-test measurements of the experimental group in the level of the studied composite offensive basketball skills, in favor of the post-test measurement.

3. There are statistically significant differences at $p$ level 0.05 between the means of the post-test measurements of the control group and the experimental group in the level of the studied composite offensive basketball skills, in favor of the experimental group. 
4. There are differences in the improvement rates of the means of the control and experimental groups' post-test measurements in the level of the studied composite offensive basketball skills, in favor of the experimental group, and came in the following order:

- Catching and receiving the ball then passing it came in the first place with an improvement rate of $17.67 \%$.

- Catching and receiving the ball then faking then passing it came in the second place with an improvement rate of $14.67 \%$.

- Catching and receiving the ball then shooting came in the third place with an improvement rate of $13.27 \%$.

- Catching and receiving the ball then faking then shooting came in the fourth place with an improvement rate of $12.72 \%$.

\section{Recommendations:}

On the basis of the findings of this research, the researcher makes the following recommendations to benefit work in the domain of basketball:

1. Using the agility ladder is important for improving the level of composite offensive basketball skills among female students at the Faculty of Physical Education.

2. Directing the use of the agility ladder toward improving the offensive skills in basketball.

3. Further research and studies should be made about using auxiliary tools and devices in basic and composite skills of different sports.

\section{References:}

\section{A. Arabic References}

Abd Alima, H.A. (2012): The effect of some training tools on the development of the most important motor abilities related to the skills of transmission and receiving in volleyball, Journal of Physical Education Sciences, vol. 5, no. 4, Faculty of Physical Education, Babylon University

Abdel Amir, A.H. (2012): The effect of training means on the development of sensory perception, motor coordination, and accuracy of shooting forms in basketball youth players, Journal of Physical Education Sciences, vol. 5, no. 3, part II, Faculty of Physical Education, Babylon University

Abdel Dayem, M.M. \& Hassanein, M.H. (1999): New things in basketball: Scientific and applied basics, teaching, training, measurement, selection, and law, $2^{\text {nd }}$ ed. Cairo: Dar Al-Fikr Al Araby

Al-Nemr, A. \& Sayed, M.S. (1998): Basketball, Cairo: Dar Al-Asateza for publication and distribution

Abu Raya, M.A. (1999): Designing a battery of tests for composite skills performances of football players in Egypt, Unpublished Ph.D. Thesis, Faculty of Physical Education, Tanta University

Awad, Z.A. (2015): The effect of using some auxiliary tools on learning the shooting skill in basketball among preparatory school female students, Unpublished M.A. Thesis, Faculty of Physical Education, Al-Mansoura University 
Bahi, M.H. (1999): Scientific practical coefficients between theory and practice, Cairo: AlKitab center for publishing

Belal, M.A. (1997): The impact of using weighted basketballs on improving the speed and accuracy of passing and shooting among basketball youth players, Unpublished M.A. Thesis, Faculty of Physical Education for Boys, Alexandria University

Hashim, A.R. (2002): The effect of training using jump squat exercises with weights and depth jump exercises on the height of vertical jump in basketball players, Unpublished Ph.D., Faculty of Physical Education for Boys, Helwan University, Cairo

Hassanein, M.S. (1987): Evaluation and measurement in Physical Education, Part I, $2^{\text {nd }}$ ed. Cairo: Dar Al-Fikr Al-Araby

Jasim, M.H. (2008): The effect of using an auxiliary tool on developing the accuracy of scoring a goal from a free throw in basketball, Journal of Physical Education Sciences, vol. 1, no. 7, Faculty of Physical Education, Babylon University

Kapoh, N.M. (2007a): The effect of a proposed program for circuit weight training on the level of some physiological and skills variables among basketball female players, Unpublished Ph.D. Thesis, Faculty of Physical Education, Menoufeya University

Kapoh, N.M. (2007b): Determining the normative levels of some composite offensive skills tests for basketball female players, Scientific Journal of the Faculty of Physical Education for Girls, Faculty of Physical Education for Girls, Zagazig University

Moawad, H.A. (1980): Basketball for All, $6^{\text {th }}$ ed., Cairo: Dar Al-Maarif

Mohamed, M.M. (1998): The effect of depth jump exercises on the vertical jump, skills performance, shooting, and following up in basketball, Conference of Sports and Developing the Arab Society and the Requirements of the $21^{\text {st }}$ Century, vol. 3, Faculty of Physical Education for Girls, Helwan University

Shams Eddin, M.M. (1994): The impact of a training program for special physical preparation on some physiological and skills variables in basketball youth players, Unpublished M.A. Thesis, Faculty of Physical Education for Boys, Suez Canal University, Port-Said

B. English References

Abdul Jamil, S, Aziz, N. \& Hooi, L.B. (2015): Effects Of Ladder Drills Training On Agility Performance, International Journal of Health, Physical Education and Computer Science in Sports, Vol 17, No.1.pp17-25, Sports Centre, University of Malaya, Malaysia.

Chandrakumar,N, \& Ramesh, C. (2015): Effect of ladder drill and SAQ training on speed and agility among sports club badminton players, International Journal of Applied Research, 1(12): 527-529.

Srinivasan \& Saikumar (2012): Influence of Conventional Training Program Combined With Ladder On Selected Physical Fitness And Skill Performance Variables of College Level Badminton Players, Research Journal of Physical Education, Vol 7, Sports Science is published annually by the Centre for Physical Education, Health \& Sports Science, functioning in the Faculty of Natural Sciences, University of Sindh, Jamshoro, Pakistan.

Terblanche, E. \& Venter, R. E. (2009): The effect of backward training on the speed, agility and power of netball players, South African Journal for Research in Sport, Faculty of Physical Education and Recreation, Vol 31, p. 135 - 145,

C. Online References

21- http://www.selfgrowth.com/articles/benefits-of-using-speed-and-agility-ladder. 
22- http://www.sport-fitness-advisor.com/ladder-agility-drills.html. 